\title{
Interaction of Toll-like receptors with bacterial components induces expression of CDX2 and MUC2 in rat biliary epithelium in vivo and in culture
}

\author{
Hiroko Ikeda ${ }^{1}$, Motoko Sasaki ${ }^{1}$, Akira Ishikawa ${ }^{1,2}$, Yasunori Sato ${ }^{1}$, Kenichi Harada ${ }^{1}$, Yoh Zen ${ }^{1}$, Hideaki Kazumori ${ }^{3}$ \\ and Yasuni Nakanuma ${ }^{1}$
}

The mechanism of transformation of biliary epithelium leading to intestinal metaplasia, which is significantly involved in biliary diseases, remains unclear. CDX2, an intestine-specific transcription factor, is thought to regulate intestinal mucin MUC2 (mucus core protein) expression. We took advantage of polycystic kidney (PCK) rats as a model of chronic suppurative cholangitis with intestinal metaplasia and of cultured biliary epithelial cells (BECs) from PCK rats to clarify the causal relation between bacterial components such as pathogen-associated molecular patterns (PAMPs) and the development of intestinal metaplasia of bile ducts. Histological, immunohistochemical, and in situ hybridization studies were conducted in PCK rat livers. In cultured BECs, CDX2 and MUC2 were expressed following treatment with PAMPs and inhibitors (anti-Toll-like receptor (TLR)2/TLR4 antibody, nuclear factor- $\kappa \mathrm{B}$ (NF- $\kappa \mathrm{B}$ ) inhibitor MG132). Chronic suppurative cholangitis with intestinal metaplasia developed as the PCK rats aged, and intestinal metaplasia and aberrant CDX2 and MUC2 expression developed in parallel. Intraluminal bacteria and the expression of TLR2 and TLR4 in BECs were demonstrated in the bile ducts, showing chronic suppurative cholangitis. In cultured BECs, treatment with PAMPs induced upregulation of CDX2 and MUC2 expression, and this effect was abolished by pretreatment with anti-TLR2 and anti-TLR4 antibody and MG132. A knockdown of CDX2 by CDX2 small interfering RNA inhibited MUC2 expression in cultured BECs induced by PAMPs, and transfection of CDX2 expression vector induced MUC2 expression. In conclusion, bacterial components may induce upregulation of the CDX2 expression followed by MUC2 expression via TLR and the NF- $\kappa$ B system in cultured BECs, and could be related to the development of intestinal metaplasia of the bile ducts.

Laboratory Investigation (2007) 87, 559-571; doi:10.1038/labinvest.3700556; published online 9 April 2007

KEYWORDS: chronic suppurative cholangitis; intestinal metaplasia; mucus core protein 2; CDX2; biliary epithelial cells

Mucus core protein (MUC) forms the backbone protein of mucin. Sixteen types of MUC have been identified. Intestinal metaplasia associated with the aberrant expression of $\mathrm{MUC} 2^{1-4}$ is reportedly involved in tumorigenesis in several organs. Recent studies revealed that CDX2, a caudalrelated homeobox gene encoding an intestine-specific transcription factor, is a regulatory factor of intestinal development and expression of intestinal genes including MUC2 and is involved in intestinal metaplasia. ${ }^{2,4,5-8}$ CDX2dependent intestinal metaplasia is noted in Barrett's esophagus with MUC2 expression, and bile acid and chronic acid exposure have been reported to induce CDX2 expression. ${ }^{2,4-6,8,9}$
Intestinal metaplasia is also involved in the pathogenesis of biliary diseases. For example, in chronic cholangitis such as hepatolithiasis, intestinal metaplasia with goblet cells occurs, and MUC2 is aberrantly expressed in goblet cells colocalized with CDX2. ${ }^{1,10-18}$ Bacterial infections are implicated in chronic cholangitis with intestinal metaplasia. ${ }^{19,20}$ Lipopolysaccharide (LPS), a bacterial component, is known to cause MUC2 overexpression in cultured biliary epithelial cells (BECs). ${ }^{21}$ Reportedly, Toll-like receptors (TLRs) play an important role as receptors recognizing pathogen-associated molecular patterns (PAMPs) such as LPS, lipoteichoic acid (LTA), and peptidoglycan (PGN). Among them, TLR2 mediates signal transduction for LTA, PGN, and synthetic

\footnotetext{
${ }^{1}$ Department of Human Pathology, Kanazawa University Graduate School of Medicine, Kanazawa, Japan; ${ }^{2}$ Department of Surgery, Nagoya University Graduate School of Medicine, Nagoya, Japan and ${ }^{3}$ Department of Gastroenterology and Hepatology, Shimane University, School of Medicine, Izumo, Japan

Correspondence: Dr Y Nakanuma, MD, Department of Human Pathology, Kanazawa University Graduate School of Medicine, Takaramachi 13-1, Kanazawa 920-8640, Japan. E-mail: pbcpsc@kenroku.kanazawa-u.ac.jp

Received 20 January 2007; accepted 6 February 2007
} 
lipopeptide Pam3Cys-sKKKK $\times 3 \mathrm{HCl}(\mathrm{Pam} 3)$, and TLR4 is a receptor for LPS. $^{22-24}$ So far, the molecular mechanism of intestinal metaplasia and aberrant expression of CDX2 and MUC2 in bile ducts, particularly their relation to bacterial components, remain unexplored.

In this study, the participation of MUC2, CDX2, TLR, and bacterial products in biliary intestinal metaplasia was examined, by using polycystic kidney (PCK) rats which are an animal model of Caroli's disease showing multiple dilatation of intrahepatic bile ducts with chronic cholangitis and also cultured BECs from PCK rats. ${ }^{25}$

\section{MATERIALS AND METHODS PCK and Crj:CD Rats}

All rats were obtained from Charles River Japan (Sagamihara, Japan), and handled according to the Guidelines for the Care and Use of Laboratory Animals of the Kanazawa University. Crj:CD rats were used as controls. These rats were killed in sequence from 18 days of gestation to 16 months (Table 1 ).

Table 1 Chronic suppurative cholangitis and intestinal metaplasia in biliary epithelial cells of PCK rats

Age (n) \begin{tabular}{c}
$\begin{array}{c}\text { Chronic suppurative } \\
\text { cholangitis }\end{array}$ \\
$\frac{\begin{array}{c}\text { Chronic } \\
\text { inflammation }\end{array}}{\begin{array}{c}\text { Suppurative } \\
\text { cholangitis }\end{array}}$ \\
\hline
\end{tabular}

$\begin{array}{lrccc}\text { PCK rats } & & & & \\ \text { Fetus } & 40 & 0 & 0 & 0 \\ \text { 0-5 weeks } & 42 & 0 & 0 & 0 \\ \text { 6-10 weeks } & 15 & 3(20 \%) & 2(13 \%) & 1(7 \%) \\ 4-7 \text { months } & 15 & 10(67 \%)^{a, b} & 9(60 \%)^{b, c} & 4(27 \%) \\ 9-10 \text { months } & 30 & 22(73 \%)^{a, b} & 22(73 \%)^{a, b} & 21(70 \%)^{a, b, d} \\ 12-18 \text { months } & 9 & 9(100 \%)^{a, b} & 9(100 \%)^{a, b, e} & 9(100 \%)^{a, b, d}\end{array}$

\begin{tabular}{lllll} 
Control rats & & & & \\
Fetus & 8 & 0 & 0 & 0 \\
$0-5$ weeks & 8 & 0 & 0 & 0 \\
$6-10$ weeks & 9 & 0 & 0 & 0 \\
$4-7$ months & 5 & 0 & 0 & 0 \\
$9-10$ months & 5 & 0 & 0 & 0 \\
$12-18$ months & 5 & 0 & 0 & 0 \\
\hline
\end{tabular}

PCK, polycystic kidney; PMN, polymorphonuclear leukocytes.

Fetus means rats from 18 to 21 days of gestation; suppurative cholangitis was regarded as cholangitis with infiltration of PMNs in biliary lumen.

${ }^{\mathrm{a}} P<0.01$ compared with control rats at each age.

${ }^{\mathrm{b}} P<0.01$ compared with $6-10$ weeks in PCK rats.

${ }^{\mathrm{C}} P<0.05$ compared with control rats at each age.

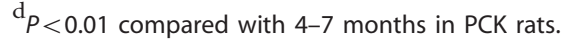

${ }^{\mathrm{e}} P<0.05$ compared with $4-7$ months in PCK rats.
Tissues

Sections from each liver were fixed in $10 \%$ formalin. More than 20 thin sections were cut from each paraffin block, and some were processed for histologic study by hematoxylineosin (H\&E), periodic acid Schiff (PAS), and Gram's staining. The intrahepatic bile ducts were examined. The rest were used for immunohistochemistry. Parts of fresh liver from PCK and control rats were used for Western blotting. The biliary trees were isolated from the liver of PCK rats by perfusion with collagenase solution as described previously. ${ }^{21}$

Bile

Bile samples that were obtained from the common bile duct lumen of PCK rats by cannulation were used for the identification of bacterial species.

\section{Culture of BECs}

Intrahepatic BECs were isolated from 8-week-old male PCK and control rats, and cultured. ${ }^{21}$ Subcultured BECs from the 6th to 9th passage were used. There were no goblet cells or MUC2-positive cells among the isolated BECs.

\section{Antibodies and Other Reagents}

Antibodies and reagents are shown in Table 2. Among them, anti-CDX2 antibody against human tissue is reported to react with rat $\mathrm{CDX} 2,{ }^{8,9}$ and our preliminary study also confirmed that this antibody reacted with the nuclei of cell of the small intestinal epithelium of PCK rats. Therefore, we used this antibody in this study using rat specimens.

\section{Immunohistochemistry}

MUC2, CDX2, TLR2, and TLR4 expression were examined immunohistochemically in the bile ducts from livers from 60 PCK rats ( 6 weeks to 10 months) and in cultured BECs on collagen gel. The latter were fixed in paraformaldehyde, and more than 20 thin sections were cut from each paraffin block. Briefly, deparaffinized sections were microwaved in citrate buffer for MUC2 and CDX2, and were treated with proteinase $\mathrm{K}$ for TLR2 and TLR4. These sections were then incubated with each primary antibody, and incubated with goat anti-mouse or rabbit immunoglobulins conjugated to peroxidase-labeled polymer (Envision +$)$. Diaminobenzidine tetrahydrochloride was used as a chromogen.

Double fluorescent immunostaining for MUC2 and CDX2 was performed using three PCK rats expressing MUC2 and CDX2 in the bile ducts and cultured BECs. Deparaffinized sections were microwaved in citrate buffer, and then incubated with rabbit polyclonal antibody to MUC2 and mouse monoclonal antibody to CDX2. After incubation with Alexa Fluor 488 goat anti-rabbit immunoglobulin G (IgG) and Alexa Fluor 594 goat anti-mouse IgG, nuclei were stained by 4',6-diamino-2-phenylindole, dihydrochloride (DAPI), and examined under a confocal laser microscope LSM5 (Carl Zeiss, Oberkochen, Germany). 
Small intestinal samples of PCK rats served as positive controls for CDX2 immunostaining. Negative controls were evaluated using normal mouse or rabbit serum.

\section{In Situ Hybridization for MUC2 and CDX2 mRNA}

Digoxigenin-labeled RNA probes for MUC2 and CDX2 were made by in vitro transcription using reverse transcriptionpolymerase chain reaction (RT-PCR) products as a template (Boehringer Mannheim, Mannheim, Germany) and SP6/T7 RNA polymerases. ${ }^{14}$ PCR primers used were as follows: MUC2 forward, 5'-ACTCACTATAGGGAGACTGGTAGAGG AGATTACCCCC- $3^{\prime}$; reverse, $5^{\prime}$-ACTCACTATAGGGAGATCA CATGTGGTCAGGTTGC-3'; CDX2 forward, 5'-ACTCACTA TAGGGAGACCACCGCCGCCGCAGAACAG- ${ }^{\prime}$; reverse, $5^{\prime}$-ACT CACTATAGGGAGACCCCGCCCGCCCCAACC- $3^{\prime}$. Briefly, deparaffinized sections of PCK and control rats were treated with proteinase $\mathrm{K}$, and then dehydration and hybridization were performed.

\section{Western Blotting}

Protein was extracted from fresh whole livers, freshly isolated biliary trees, and cultured BECs isolated from 8-week-old PCK rats, using Tissue Protein Extraction Reagent, ${ }^{21}$ and total protein was measured spectrometrically. Anti-CDX2 antibody, anti-MUC2 antibody, and anti- $\beta$-actin antibody were used as the primary antibody. CDX2 protein was specifically concentrated by the immunoprecipitation using primary antibody to CDX2 and protein G-agarose beads (Roche, Indianapolis, IN, USA). Immunoblots were visualized with an enhanced chemiluminescence system.

\section{RT-PCR}

Total RNA was extracted from cultured BECs by using the RNeasy Total RNA System. After complementary DNA was synthesized, a semiquantitative RT-PCR was carried out. The sequence of the primers and conditions for PCR are shown in Table 3. The density of band(s) was semiquantitatively analyzed, using NIH image.

Table 2 Antibodies and commercially purchased reagents used in this study

\begin{tabular}{|c|c|c|c|c|c|}
\hline & Source & $\begin{array}{l}\text { Type of } \\
\text { antibody }\end{array}$ & $\begin{array}{l}\text { Animals } \\
\text { immunized }\end{array}$ & $\begin{array}{l}\text { Specificity } \\
\text { of antibody }\end{array}$ & $\begin{array}{l}\text { Optimal dilution/ } \\
\text { concentration }\end{array}$ \\
\hline Anti-MUC2 $^{\mathrm{a}}$ & Santa Cruz Biotechnology (Santa Cruz, CA, USA) & Poly & Rabbit (lgG) & Mouse, rat, and human & 1:100 \\
\hline Anti-MUC2 ${ }^{\mathrm{b}}$ & Santa Cruz Biotechnology (Santa Cruz, CA, USA) & Poly & Goat (lgG) & Mouse, rat, and human & 1:100 \\
\hline Anti-CDX2 $2^{a, b}$ & BioGenex (SanRamon, CA, USA) & Mono & Mouse (lgG) & Human & 1:100 \\
\hline Anti-TLR2 ${ }^{\mathrm{a}, \mathrm{c}}$ & Santa Cruz Biotechnology (Santa Cruz, CA, USA) & Poly & Rabbit (lgG) & Mouse, rat, and human & 1:100 \\
\hline Anti-TLR4 $4^{\mathrm{a}, \mathrm{c}}$ & Santa Cruz Biotechnology (Santa Cruz, CA, USA) & Poly & Rabbit (lgG) & Human, mouse, and rat & 1:100 \\
\hline Anti- $\beta$-actin ${ }^{\mathrm{b}}$ & Abcam (Cambridge, UK) & Mono & Mouse (lgG) & Various species & 1:5000 \\
\hline Envision+ & DAKO (Tokyo, Japan) & & & & \\
\hline DAPI & Molecular Probes (Eugene, OR, USA) & & & & 1:500 \\
\hline SP6/7 RNA polymerase & Promega Corporation (Madison, WI, USA) & & & & \\
\hline T-PER & Pierce (Rockkford, IL, USA) & & & & \\
\hline RNeasy total RNA system & Qiagen (Hilden, Germany) & & & & \\
\hline LPS & Sigma (from Escherichia coli serotype 055:B5) & & & & $0.1-10 \mu \mathrm{g} / \mathrm{ml}$ \\
\hline LTA & Sigma (from Streptococcus faecalis) & & & & $100 \mu \mathrm{g} / \mathrm{ml}$ \\
\hline PGN & Sigma (from Staphylococcus aureus) & & & & $100 \mu \mathrm{g} / \mathrm{ml}$ \\
\hline Pam3 & EMC microcollections (Tubingen, Germany) & & & & $0.1-10 \mu \mathrm{g} / \mathrm{ml}$ \\
\hline MG132 & Calbiochem (San Diego, CA, USA) & & & & $1 \mu \mathrm{M}$ \\
\hline SiRNA & Qiagen (Hilden, Germany) & & & & \\
\hline DreamFect $^{\mathrm{TM}}$ & OZ Bioscience (Marseilles, France) & & & & \\
\hline OPTI-MEMI & Life Technologies (Rockville, MD, USA) & & & & \\
\hline FUGENE 6 & Roche Diagnostics (Indianapolis, IN, USA) & & & & \\
\hline
\end{tabular}

DAPI, 4',6-diamino-2-phenylindole, dihydrochloride; IgG, immunoglobulin G; LPS, lipopolysaccharide; LTA, lipoteichoic acid; Pam3, Pam3Cys-SKKKK × 3HCl; PGN, peptidoglycan; siRNA, small interfering RNA; T-PER, tissue protein extraction reagent.

a Used for immunohistochemical staining.

bused for Western blot study.

${ }^{\mathrm{C}}$ Used for neutralization study. 
Table 3 Sequence of the primers and PCR conditions used in this study

\begin{tabular}{|c|c|c|c|c|}
\hline Gene & Sequence $\left(5^{\prime}-3^{\prime}\right)$ forward/reverse & Product size (bp) & Annealing temperature $\left({ }^{\circ} \mathrm{C}\right)$ & PCR cycles \\
\hline \multirow[t]{2}{*}{ MUC2 } & CTGGTACACCACATTACCCCC & 1100 & 60 & 40 \\
\hline & TCACATGTGGTCAGGTTGC & & & \\
\hline \multirow[t]{2}{*}{ CDX2 } & CCACCGCCGCCGCAGAACAG & 905 & 65 & 40 \\
\hline & CCCCGCCCGCCCCAACC & & & \\
\hline \multirow[t]{2}{*}{ TLR2 } & GGAGACTCTGGAAGCAGGTG & 245 & 60 & 30 \\
\hline & CGCCTAAGAGCAGGATCAAC & & & \\
\hline \multirow[t]{2}{*}{ TLR4 } & GCCGGAAAGTTATTGTGGTG & 205 & 60 & 30 \\
\hline & TCCCACTCGAGGTAGGTGTT & & & \\
\hline \multirow[t]{2}{*}{ CK19 } & GACTTCCTATAGCTATCGCC & 359 & 60 & 25 \\
\hline & TCTGGTACCAGTCGCGAATC & & & \\
\hline \multirow[t]{2}{*}{$\beta$-Actin } & ACCTTCAACACCCCAGCCATGTACG & 910 & 60 & 20 \\
\hline & CTGATCCACATCTGCTGGAAGGTGG & & & \\
\hline
\end{tabular}

Treatment with PAMPs and Nuclear Factor- $\kappa$ B Inhibitors in Cultured BECs

When cultured BECs reached a semiconfluent state, LPS, Pam3, LTA, or PGN was added. Then, MUC2 and CDX2 expression in BECs was examined by RT-PCR, Western blotting, and immunohistochemistry.

To assess the involvement of TLR, BECs were preincubated with polyclonal rabbit anti-rat TLR2/TLR4 antibody or control IgG as a negative control, and then incubated with Pam3/LPS. To examine the involvement of the nuclear factor$\kappa \mathrm{B}(\mathrm{NF}-\kappa \mathrm{B})$ signaling pathway in MUC2 and CDX2 expression in BECs induced by PAMPs, BECs were pretreated with MG132 as an inhibitor of NF- $\kappa \mathrm{B}$, and then treated with LPS. Then, MUC2 and CDX2 expression in BECs was evaluated by RT-PCR and Western blotting.

\section{Transfection Study}

\section{Transfection of CDX2 small interfering RNA}

Small interfering RNA (siRNA) for rat CDX2 and scramble siRNA as a negative control were purchased from Qiagen. The target sequence of rat CDX2 was $5^{\prime}$-CTGGTCTGTGTAA CAAGCCAA- $3^{\prime}$, corresponding to the coding region 1870 1890. The siRNA was transfected into cultured BECs with DreamFect $^{\mathrm{TM}}$. Briefly, $20 \mu \mathrm{l}$ of $20 \mu \mathrm{M}$ siRNA was diluted with $100 \mu \mathrm{l}$ of OPTI-MEMI. DreamFect ${ }^{\mathrm{TM}}$ was added to the siRNA, and gently mixed. The mixture was added to the culture medium with BECs. At 24 and $30 \mathrm{~h}$ after transfection, several groups of cultured BECs were treated with LPS, and cultured BECs were harvested, respectively.

\section{Transfection of CDX2 expression vector}

A CDX2 expression plasmid was constructed as described previously. ${ }^{8}$ Empty vector was used as a negative control. Cultured BECs were transfected with this expression vector, using FuGENE 6 Transfection Reagent. Briefly, FuGENE 6
Reagent was diluted with OPTI-MEMI, and gently mixed. An amount of $2 \mu \mathrm{g}$ of expression or empty vector was added to the diluted FuGENE 6 Reagent and incubated. The mixture was added to $2 \mathrm{ml}$ of culture medium with BECs. At $24 \mathrm{~h}$ after transfection, BECs were harvested for RT-PCR and at $72 \mathrm{~h}$ after transfection, BECs were harvested for immunoblotting.

\section{Identification of Bacterial Species in Bile}

The identification of bacterial species in bile samples from PCK rats (10 months) was performed by PCR amplification with bacterial universal primers and sequencing as described previously. ${ }^{26}$ Homology searches were performed with the alignment search tool BLAST on internet database (http:// www.blast.genome.ad.jp/).

\section{Statistical Analysis}

The Welch $t$-test or the Student's $t$-test and $\chi^{2}$ were used. $P<0.05$ was regarded as significant.

\section{RESULTS}

\section{Animal Studies}

Histology

Multiple dilatation of intrahepatic bile ducts and fibrous expansion of portal tracts were observed in PCK rats. ${ }^{25} \mathrm{At}$ around 6 weeks, variable lymphocytic infiltration was focally seen around the dilated bile ducts (Figure 1a). After 4-7 months, chronic cholangitis with suppurative changes and polymorphonuclear leukocytes (PMNs) in duct lumen (chronic suppurative cholangitis) became frequent, and at around 12-18 months, such changes were widespread in all PCK rats (Figure 1b). The extent of chronic suppurative cholangitis with bile duct dilatation increased gradually with aging $(P<0.05)$ (Table 1$)$, and colonies of Gram-negative and/or -positive bacteria were identifiable in the duct lumen (Figure 1c). Intestinal metaplasia with goblet cells was fre- 

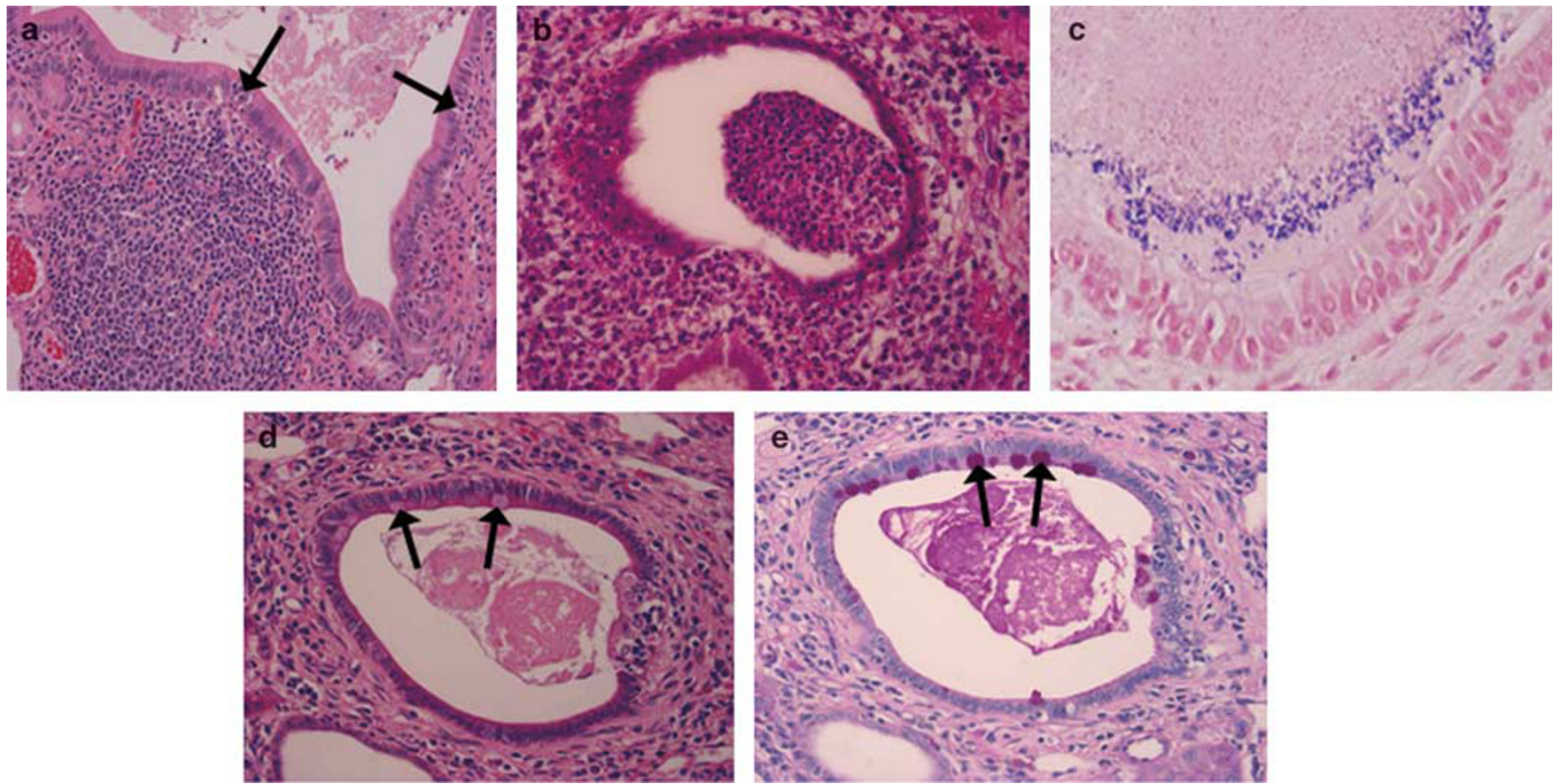

Figure 1 Histopathological findings of the liver of PCK rats. (a) The intrahepatic bile duct shows chronic cholangitis with lymph-follicle-like aggregation, and lymphocytes infiltrate the biliary epithelial layer (arrows). PCK rat at 6 weeks. H\&E, $\times 200$. (b) Clusters of PMNs are seen in the lumen of the bile duct surrounded by many PMNs. PCK rat at 6 weeks. H\&E, $\times 200$. (c) Gram-positive and -negative bacteria are mixed in the bile duct lumen. PCK rat at 6 weeks. Gram staining, $\times 400$. (d) Intestinal metaplasia containing goblet cells (arrows) are observed in the bile ducts with infiltration of lymphocytes and PMNs. PCK rat at 10 months. H\&E, $\times 200$. (e) Mucin in the cytoplasm of goblet cells (arrows) and in the bile duct lumen (asterisk) are positive for PAS staining. PAS, $\times 200$.

quently found in the affected ducts (Figure 1d and e). None of these changes were present in control rats.

\section{Expression of MUC2 and CDX2}

MUC2 and CDX2 were immunohistochemically detected in BECs of the bile ducts showing chronic suppurative cholangitis and intestinal metaplasia. MUC2 was expressed in the cytoplasm of goblet cells, whereas CDX2 was expressed in the nuclei of goblet cells and adjacent columnar epithelial cells (Figure $2 \mathrm{a}-\mathrm{c}$ ). There was no expression of MUC2 or CDX2 in other histologic components or cells in the liver except for BECs.

By in situ hybridization (ISH), MUC2 and CDX2 mRNA were detected in the cytoplasm of goblet cells and in the cytoplasm of goblet cells and adjacent columnar epithelial cells, respectively (Figure 2d and f). The distribution of mRNA-positive cells was the same as that of MUC2 and CDX2 protein-expressing cells. No signals were detected in these cells, when sense probes were used (Figure 2e and g).

By Western blotting, CDX2 protein was detected in the whole liver tissue of PCK rats with marked chronic suppurative cholangitis and intestinal metaplasia at 10 and 16 months (Figure 3a). In contrast, weak expression of CDX2 was seen in the liver tissue from PCK rats showing mild chronic cholangitis and no intestinal metaplasia. The liver samples from PCK rats showing no cholangitis and from control rats were negative for CDX2. Likewise, CDX2 protein was not detectable in the freshly isolated biliary tree from PCK rats showing cholangitis and intestinal metaplasia at 8 months (Figure $3 b$ ).

\section{Expression of TLR2 and TLR4}

Immunohistochemically, TLR2 expression was barely seen in BECs of the ducts of control rats and PCK rats showing no inflammatory changes (Figure 4a). In contrast, expression of TLR2 was evident in the cytoplasm and at the luminal surface of BECs in the affected ducts (Figure 4b). TLR4 was expressed constitutively in the cytoplasm and at the luminal surface of BECs in the ducts of control and PCK rats (Figure $4 \mathrm{c}$ and $\mathrm{d})$.

\section{Detection and identification of bacterial species}

By sequencing, 16S ribosomal RNA gene of Corynebacterium species (GenBank, Y09806), Pasteurella pneumotropica (GenBank AF012090), and Enterococcus faecalis (GenBank, Y18293) were detected in the bile samples from PCK rats.

\section{Cultural Studies}

Treatment with PAMPs and expression of CDX2 and MUC2 CDX2 and MUC2 at the mRNA and protein level were not detected in cultured BECs without treatment. Treatment with LPS, Pam3, LTA, and PGN upregulated CDX2 and MUC2 mRNA and protein expression in BECs (Figure $5 \mathrm{a}$ and $\mathrm{b}$ ). The CDX2 mRNA level in BECs treated with LPS increased in 

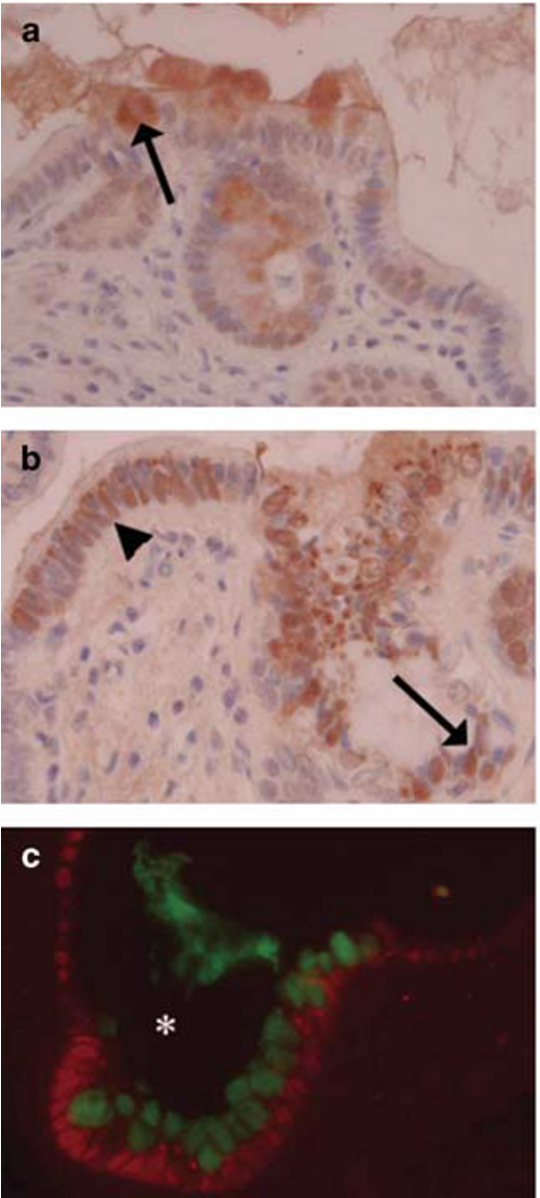
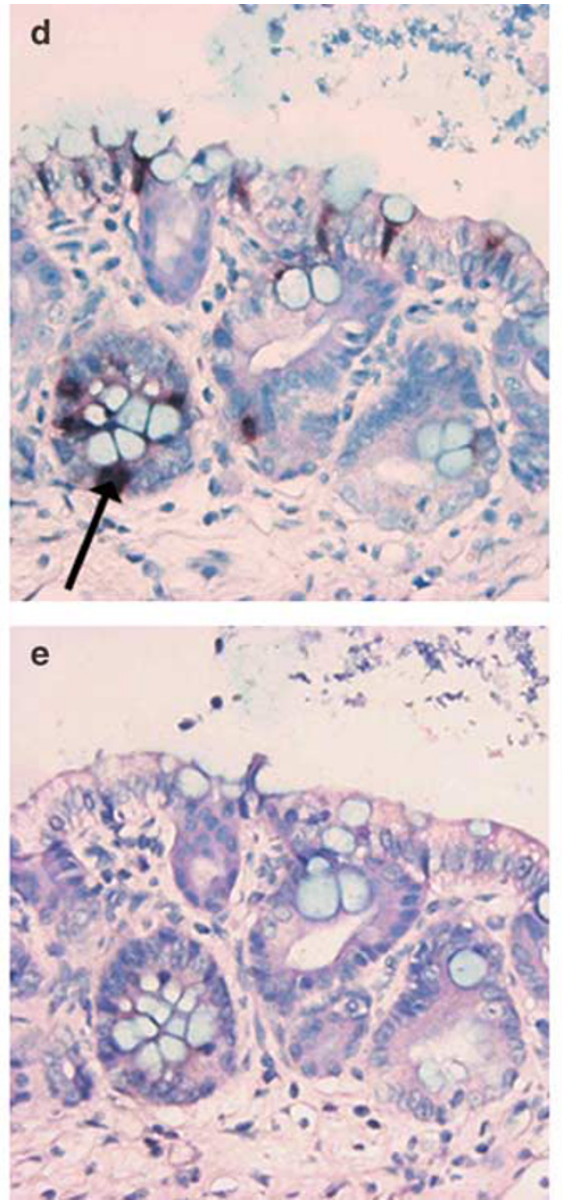
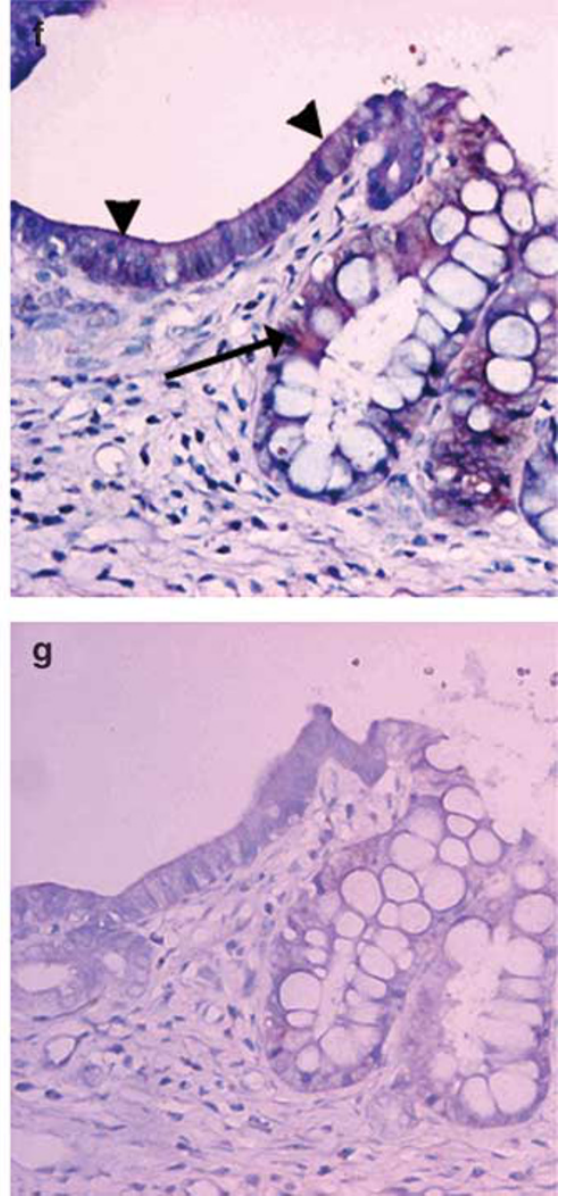

Figure 2 Expression of MUC2 or CDX2 protein and mRNA level at intestinal metaplasia of the intrahepatic bile ducts of PCK rats at 10 months. (a-c) Immunohistochemistry for MUC2 (a) and CDX2 (b), and double fluorescence immunohistochemistry for MUC2 and CDX2 (c). (a) MUC2 is expressed in the cytoplasmic mucin of goblet cells (arrow) and also secreted in the lumen. Counterstained with hematoxylin, $\times 400$. (b) CDX2 is expressed in the nuclei of goblet cells (arrow) and of surrounding columnar BECs (arrowhead). Counterstained with hematoxylin, $\times 400$. (c) Double fluorescence immunostaining for MUC2 (green) and CDX2 (red). In goblet cells, MUC2 in the cytoplasm and CDX2 in the nucleus are coexpressed. In nuclei of some columnar BECs around goblet cells, CDX2 is expressed, whereas MUC2 expression is not evident. ${ }^{*}$ Lumen of the bile duct. $\times 400$. (d-g) ISH for MUC2 mRNA with antisense (d) and sense (e) probes and for CDX2 with antisense (f) and sense (g) probes. Positive staining of MUC2 and CDX2 mRNA is evident in the cytoplasm of goblet cells ( $\mathbf{d}$ and $\mathbf{f}$, arrows). The signals of CDX2 mRNA are also seen in the cytoplasm of columnar BECs around goblet cells (f, arrowheads). These signals were not detected when the slides were hybridized with sense probes (e and $\mathbf{g})$. (d-g) Counterstained with methyl green, $\times 400$.

a dose-dependent manner (Figure 5c). Treatment with Pam3 upregulated CDX2 mRNA and MUC2 mRNA expression (Figure 5d). CDX2 and MUC2 were immunohistochemically detected in nuclei and cytoplasm of the same BECs (Figure 5e). Taken together, MUC2 expression in BECs induced by PAMPs was closely associated with CDX2 expression.

\section{Involvement of TLRs in PAMPs-induced CDX2 and MUC2 expression}

TLR2 and TLR4 at the mRNA and protein level were detected in BECs without treatment (Figure $6 \mathrm{a}$ and b). Preincubation with anti-TLR4 antibody inhibited almost completely the expression of CDX2 and MUC2 mRNA in BECs incubated with LPS, and similar pretreatment with anti-TLR2 antibody before incubation with Pam3 resulted in incomplete and complete inhibition of CDX2 mRNA and MUC2 mRNA expression, respectively (Figure $6 \mathrm{c}$ and $\mathrm{d}$ ). In contrast, addition of normal rabbit IgG failed to have such inhibitory effects. Inhibition of LPS/Pam3-induced CDX2 and MUC2 expression with anti-TLR4/TLR2 antibody was also evident at the protein level (Figure 6e and $\mathrm{f}$ ). In cultured BECs from control rats, LPS induced also CDX2 and MUC2 mRNA, and the expression was inhibited by anti-TLR4 antibody as seen in cultured BECs from PCK rats (Figure $6 \mathrm{~g}$ ).

LPS-induced CDX2 and MUC2 expression and NF- $\kappa B$ inhibitor Pretreatment of BECs with MG132 reduced the upregulated expression of CDX2 and MUC2 mRNA induced by LPS (Figure 7a), and this reduction was also shown semiquantitatively $(<0.05)$ (Figure $7 \mathrm{~b})$. LPS-induced CDX2 and MUC2 protein expression was also inhibited with MG132 preincubation (Figure 7c). 
a

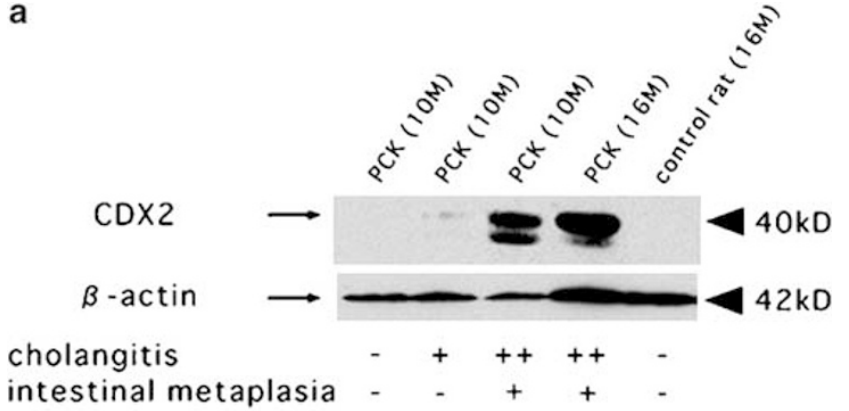

b

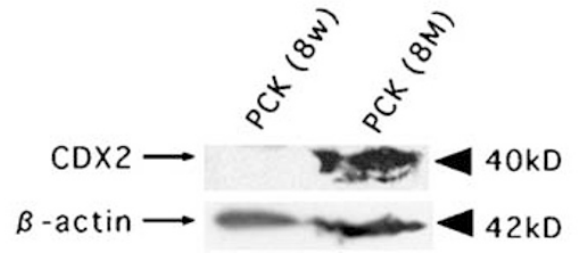

Figure 3 Western blot analysis for CDX2 protein in rat liver tissue. (a) Positive signals for CDX2 protein $(40 \mathrm{kDa})$ are detected in the liver of PCK rats showing chronic suppurative cholangitis. Expression of CDX2 is stronger in the liver tissues that show moderate to severe cholangitis and intestinal metaplasia (10 months $(\mathrm{M})$ and $16 \mathrm{M}$ ), whereas CDX2 is weakly detected in PCK rat with mild cholangitis but no intestinal metaplasia (10M). CDX2 protein is not detected in samples of PCK rat with no cholangitis or intestinal metaplasia and also the control rat. Expression of $\beta$-actin $(42 \mathrm{kDa}$ ) was detected in all samples. (b) CDX2 is detectable in the biliary tree freshly isolated from the liver of PCK rat showing cholangitis and intestinal metaplasia at 8 months (right lane). Instead, CDX2 protein is not detectable in the cultured BECs freshly isolated from the liver of PCK rat at 8 weeks without cholangitis (left lane).

\section{Transfection Study on Expression of CDX2 and MUC2 in} Cultured BECs

LPS-induced CDX2 and MUC2 mRNA expression disappeared in BECs transfected with CDX2 siRNA, but not in cells transfected with control siRNA (Figure 8), indicating that LPS induced MUC2 expression via upregulation of CDX2. In contrast, MUC2 mRNA and protein levels increased when transfection of the CDX2 expression vector was performed in BECs (Figure 9a and b). Immunohistochemically, cultured BECs transfected with the CDX2 expression vector expressed CDX2 in the nucleus and MUC2 in the cytoplasm (Figure 9c). In cultured BECs from control rats, upregulation of the expression of MUC2 protein induced by transfection of the CDX2 expression vector was also demonstrated (Figure 9d). The level of cytokeratin 19 (CK19) mRNA, a marker of BECs, was not changed after transfection of the CDX2 expression vector.

\section{DISCUSSION}

This study showed that the intrahepatic bile ducts of PCK rats showed chronic suppurative cholangitis which became more frequent and widespread with aging. ${ }^{25}$ Interestingly, this cholangitis was frequently associated with intestinal metaplasia with goblet cells, and MUC2 and CDX2 at protein and mRNA levels were detectable. MUC2 was mainly expressed in goblet cells, and CDX2 was detectable in nuclei of goblet cells and also surrounding columnar cells. The distribution of MUC2 and CDX2 expression is similar to that in previous reports in that MUC2 expression is restricted to the cytoplasm of goblet type cells and CDX2 is expressed extensively compared with MUC2. ${ }^{1,8,17}$ CDX2 expression may be an early event in intestinal metaplasia because the expression of MUC2 is found within BECs that express CDX2. The extensive expression of CDX2 might suggest that CDX2 exists upstream in the pathogenesis of intestinal metaplasia.

In hepatolithiasis, the intrahepatic bile ducts show chronic cholangitis and intestinal metaplasia with goblet cells and aberrant MUC2 expression, and many kinds of bacteria species, especially Escherichia coli, were detected in bile of the affected ducts. ${ }^{14-16}$ MUC2 is reportedly overexpressed in response to bacterial components, such as LPS or LTA, in cultured intestinal or airway epithelial cells and also BECs. ${ }^{21,27,28}$ Therefore, it is possible that bacterial infection and/or bacterial components are responsible for the intestinal metaplasia and MUC2 expression in the affected ducts in hepatolithiasis. $^{20}$

In PCK rats, Gram-positive and -negative bacterial colonies were found in the lumen of ducts showing chronic suppurative cholangitis, and sequencing demonstrated Corynebacterium species, Enterococcus faecalis, and Pasteurella pneumotropica. The former two are normal microflora in the intestine and the latter is routinely isolated from the oral cavity in rats. It is possible that such bacterial infection or components were related to the development of intestinal metaplasia and MUC2 expression in these ducts. Cultural studies have showed that PAMPs such as LPS, Pam3, LTA, and PGN upregulated MUC2 expression in BECs of PCK rats. By using PCK rats and cultured BECs from PCK or control rats, we tried to clarify how bacterial components induce intestinal metaplasia and MUC2 expression in the ducts.

Recent studies showed that CDX2 regulates intestinal differentiation and MUC2 expression and is a key molecule for intestinal metaplasia. ${ }^{2,4-6,8}$ Ectopic expression of CDX2 is known to induce intestinal phenotypes such as MUC2 expression in Barrett's esophagus, and bile acid or chronic acid exposure was speculated to induce CDX2 expression in esophageal keratinocytes. ${ }^{8,29}$ Inflammatory cytokines and infection may also induce CDX2 and then MUC2 expression. ${ }^{2,4-6}$ For example, CDX2 expression was reportedly upregulated in cultured epithelial cells when they were infected with bacteria, and interactions of TLR with microbial components are involved in the regulation of MUC expression. ${ }^{30-35}$ Therefore, bacterial components in bile may induce CDX2 expression and then aberrant MUC2 expression in the ducts.

This study showed that treatment with PAMPs such as LPS, Pam3, LTA, and PGN upregulated CDX2 expression in cultured BECs, and the level of CDX2 mRNA was increased by LPS in a dose-dependent manner. LPS treatment induced CDX2 and MUC2 expression in the nuclei and cytoplasm of 
the same cultured BECs, respectively, suggesting that PAMPs induce CDX2 expression in BECs in association with MUC2 expression. This is consistent with the findings that intestinal
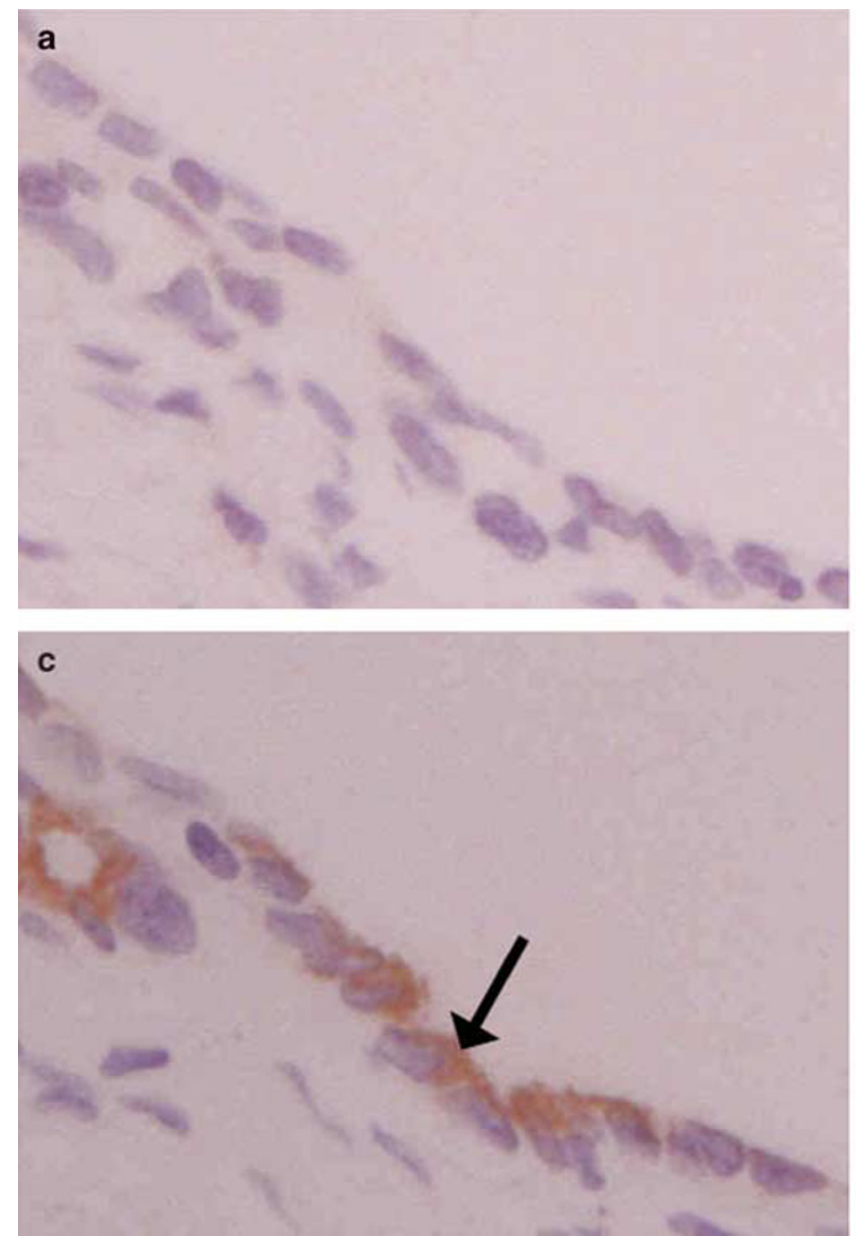

metaplasia occurred in bile ducts showing chronic suppurative cholangitis, and bacterial components were present in the duct lumen and also in bile of PCK rats.
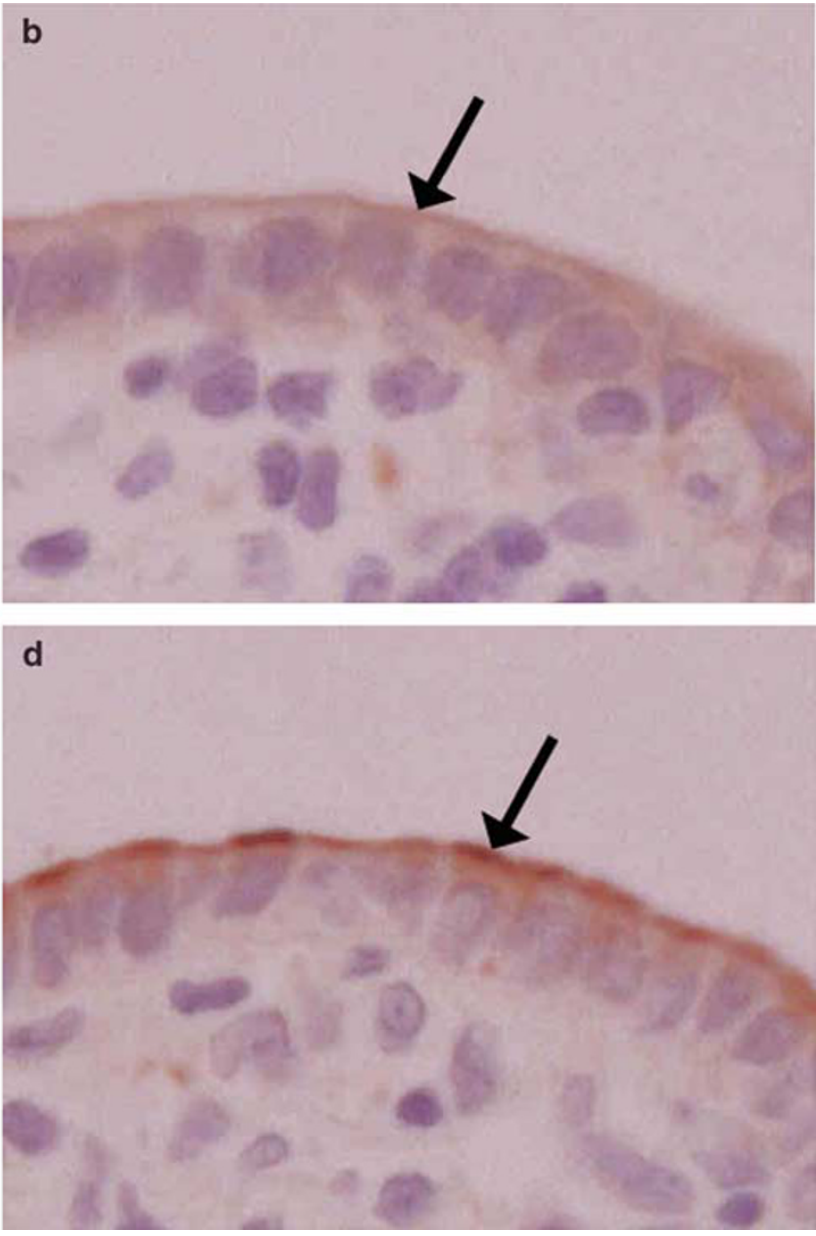

Figure 4 Immunohistochemistry for TLR2 and TLR4 in the liver of control rats (a and $\mathbf{c}$ ) and PCK rats (b and $\mathbf{d})$ at 9 months. (a) TLR2 is not expressed in the BECs (arrow) of bile ducts of control rats. (b) TLR2 is expressed in the cytoplasm and on the luminal surface of BECs (arrow) of bile ducts with moderate inflammation in PCK rats. (c) TLR4 is expressed on the luminal surface of BECs of the bile ducts in the control rat (arrow). (d) TLR4 is expressed in the cytoplasm and more intensely on the luminal surface of BECs of the bile ducts with moderate inflammation (arrow) in PCK rats. Counterstained with hematoxylin, $\times 400$.

Figure 5 Effects of PAMPs on CDX2 and MUC2 expression in cultured BECs from PCK rats. (a) CDX2 and MUC2 mRNA are not detected in the contro condition without treatment. Cultured BECs were incubated with LPS $(10 \mu \mathrm{g} / \mathrm{ml})$, synthetic lipopeptide Pam3 $(10 \mu \mathrm{g} / \mathrm{ml}), \mathrm{LTA}(100 \mu \mathrm{g} / \mathrm{ml})$, or PGN $(100 \mu \mathrm{g} /$ $\mathrm{ml}$ ) for $6 \mathrm{~h}$. All of these four PAMPs upregulated the expression of CDX2 and MUC2 mRNA, as shown by RT-PCR. (b) Expression of CDX2 and MUC2 at the protein is induced by treatment with either of the PAMPs. No positive band was detected in the control condition without treatment. Western blotting for CDX2 and MUC2. (c) Gel image and semiquantitative assessment of CDX2 and MUC2 mRNA expression with LPS treatment detected by RT-PCR. Cultured BECs were stimulated with $0.1,1$, and $10 \mu \mathrm{g} / \mathrm{ml}$ LPS for $6 \mathrm{~h}$ before assessment of CDX2 and MUC2 mRNA expression in the cell lysate. A CDX2 band is evident with $1 \mu \mathrm{g} / \mathrm{ml} \mathrm{LPS}$ and more so with $10 \mu \mathrm{g} / \mathrm{ml} \mathrm{LPS}$, whereas a band of MUC2 mRNA is present only on stimulation with $10 \mu \mathrm{g} / \mathrm{ml}$, not 0.1 or $1 \mu \mathrm{g} / \mathrm{ml}$ LPS. The relative increase in signals of CDX2 at $0.1,1$, and $10 \mu \mathrm{g} / \mathrm{ml} \mathrm{LPS}$ ) is shown in the graph. Dose-dependent increased expression of CDX2 mRNA is significantly evident. A band of MUC2 mRNA is present only on stimulation with $10 \mu \mathrm{g} / \mathrm{ml}$ but not 0.1 or $1 \mu \mathrm{g} / \mathrm{ml}$ LPS. ${ }^{*} P<0.05$, when compared with $0.1 \mu \mathrm{g} / \mathrm{ml}$ treatment, ${ }^{* * P}<0.05$, when compared with $1 \mu \mathrm{g} / \mathrm{ml}$ treatment. (d) Gel image and semiquantitative assessment of CDX2 and MUC2 mRNA expression with Pam3 treatment shown by RT-PCR. Cultured BECs were treated with Pam3 $(0.1,1$, and $10 \mu \mathrm{g} / \mathrm{ml})$ for $6 \mathrm{~h}$. Treatment with Pam3 revealed strong expression of CDX2 mRNA at all doses. A MUC2 band is weakly detected with $0.1 \mu \mathrm{g} / \mathrm{ml}$ and clearly detected with $1 \mathrm{and} 10 \mu \mathrm{g} / \mathrm{ml}$ of Pam3. The relative increase in signals of MUC2 at $0.1,1$, and $10 \mu \mathrm{g} / \mathrm{ml}$ LPS) is shown in the graph. ${ }^{*} P<0.05$, when compared with $0.1 \mu \mathrm{g} / \mathrm{ml}$ treatment. Bars indicate mean \pm s.e.m. (e) Nuclear staining of CDX2 and cytoplasmic expression of MUC2 are evident in cultured BECs after incubation of $10 \mu \mathrm{g} / \mathrm{ml}$ LPS with $48 \mathrm{~h}$ (lower lane). In the control without LPS treatment, no positive staining is seen (upper lane). Nuclei of cultured BECs are visualized with DAPI in the right lane without immunostaining Fluorescence immunocytochemistry for CDX2 and MUC2 protein in cultured BECs. Original magnifications, $\times 400$. 
TLRs are receptors recognizing PAMPs, and are reportedly expressed in the BECs of the biliary tree. ${ }^{35}$ Among them, TLR2 and TLR4 are major receptors for bacterial components. $^{22-24}$ This study also showed that in PCK rats, TLR2 was expressed in BECs of the bile ducts with chronic suppurative cholangitis, whereas TLR4 was expressed constitutively in BECs. In addition, TLR2 and TLR4 at the mRNA and protein level were detected in cultured BECs without treatment. Interestingly, preincubation with anti-TLR4 antibody or anti-TLR2 antibody downregulated CDX2 and MUC2 expression in BECs induced by LPS (a ligand for TLR4) or Pam3 (a ligand for TLR2), respectively,

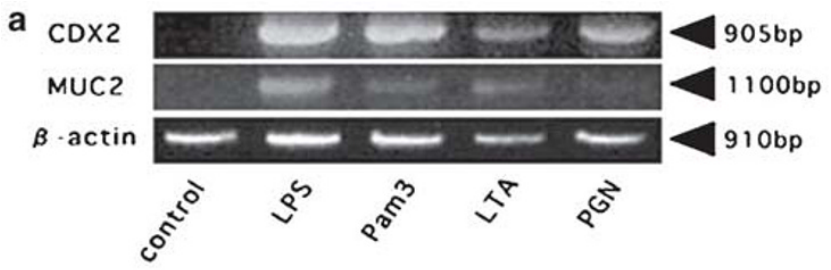

b
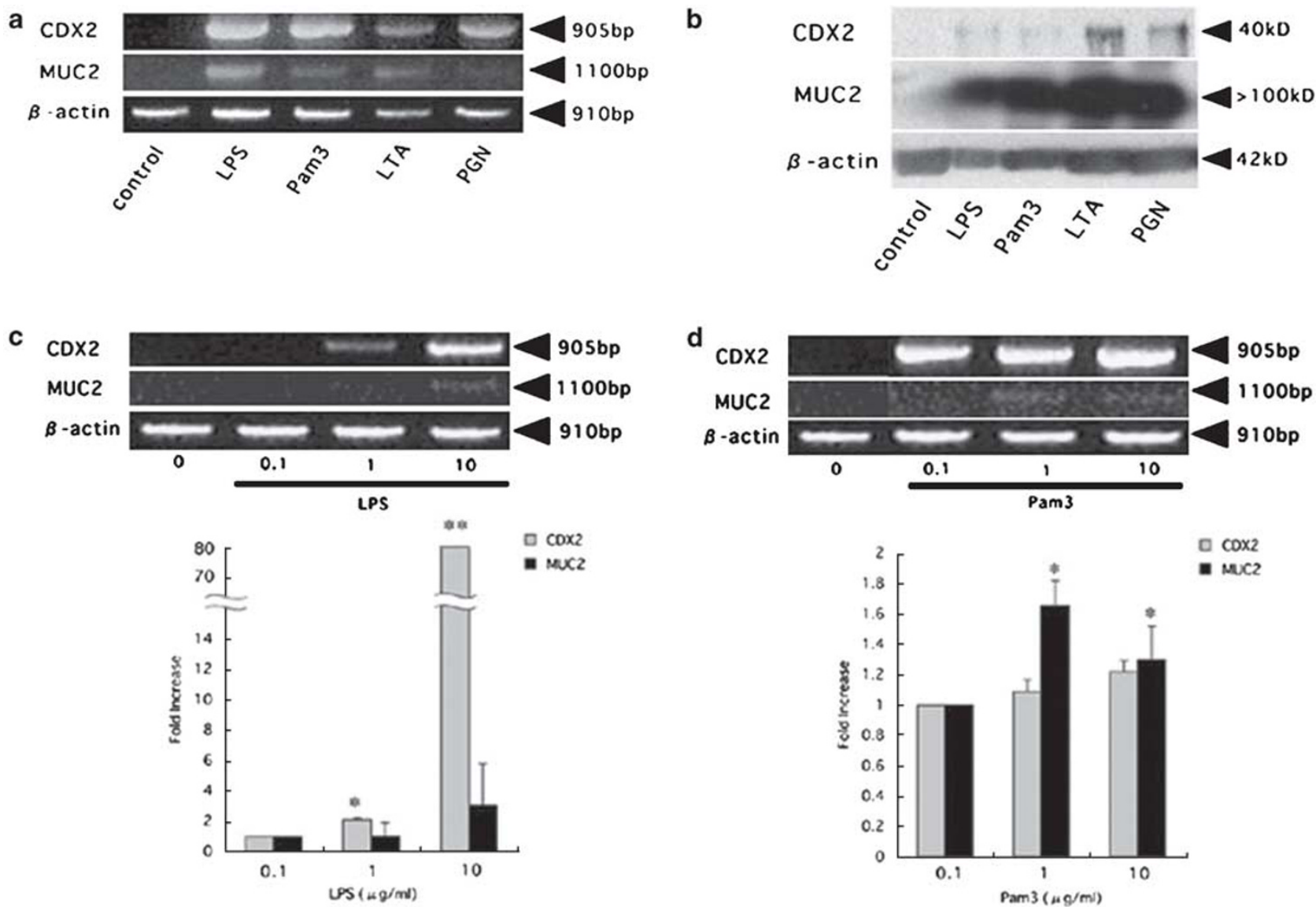

e
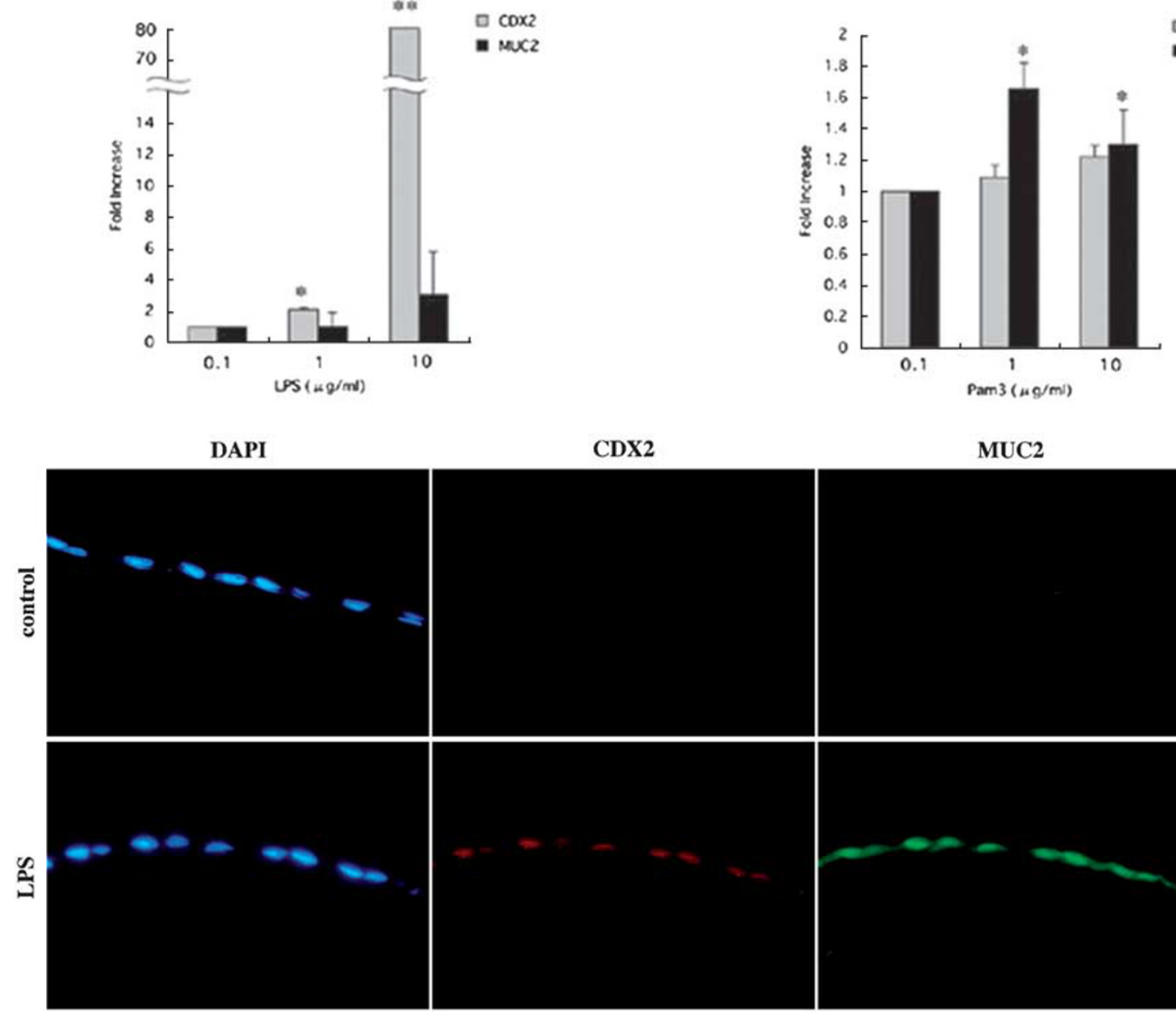

$\cos 2$

mec2

MUC2

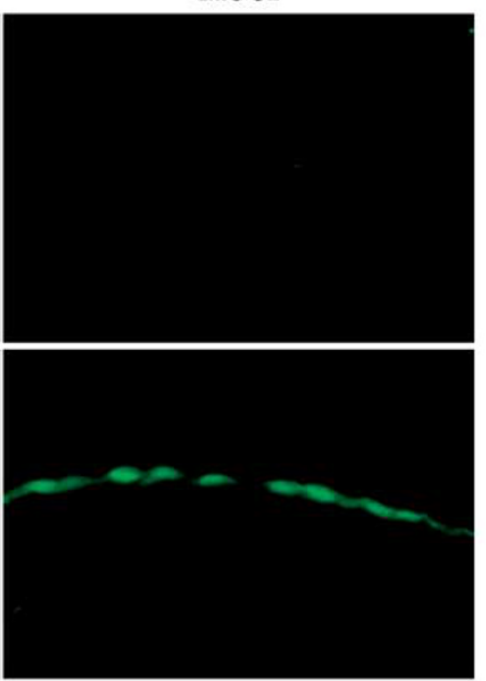


suggesting that LPS and Pam3 induced the upregulation of CDX2 and MUC2 expression in cultured BECs via TLR2 and TLR4 pathways. In cultured BECs, CDX2 and MUC2 mRNA expression levels were different to those after stimulation with LPS and Pam3. It seems plausible that the expression of CDX2 and MUC2 in BECs is related to the different receptors used against PAMPs. That is, the susceptibility and capacity of TLR2 and TLR4 in BECs to individual ligands may vary with respect to CDX2 and MUC2 expression and their response to ligands may also be influenced by the expression level of other accessory molecules such as CD14 and MD2 (accessory molecules of TLR4) in BECs.

Interaction of TLR with PAMPs is known to activate intracellular signals followed by NF- $\kappa$ B translocation and the synthesis of molecules including inflammatory cytokines. ${ }^{24,35}$ The involvement of TLR2 and/or TLR4 in Helicobacter pylori infections has been revealed in cultured gastric epithelial cell lines, ${ }^{33,34}$ in which MUC2 was induced to express by TLR2/ bacterial components and the activation of NF- $\kappa$ B. ${ }^{3,31,32}$
PAMPs-induced CDX2 and MUC2 overexpression via an NF- $\kappa$ B pathway located downstream of TLRs. This study showed that pretreatment of BECs with MG132 reduced the CDX2 and MUC2 mRNA upregulation induced by LPS, suggesting that upregulation of the CDX2 and MUC2 pathway by PAMPs was related to the activation of TLR2/ TLR4 with the translocation of NF- $\kappa$ B.

Recent studies showed that CDX2 regulates MUC2 expression. ${ }^{6,8}$ Yamamoto et al $l^{6}$ reported that transfected CDX2 expression constructs activated the MUC2 promoter and increased the MUC2 mRNA level. ${ }^{6,8}$ We showed that LPSinduced CDX2 and MUC2 mRNA expression in cultured BECs disappeared on transfection of CDX2 siRNA, and that forced expression of CDX2 by using the CDX2 expression vector upregulated MUC2 expression in cultured BECs, supporting reports that CDX2 exists upstream of MUC2 and activates transcription of MUC2. ${ }^{6,8}$ However, it is also known that MUC2 has NF- $\kappa$ B-binding sites in the promoter region, ${ }^{32,36}$ and the activation of NF- $\kappa \mathrm{B}$ could directly trigger a

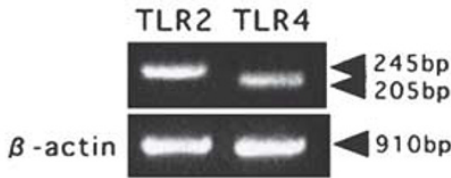

c

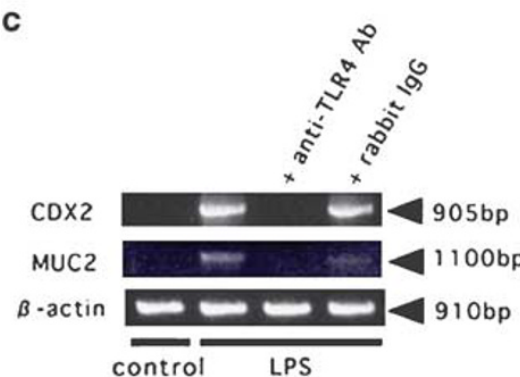

e

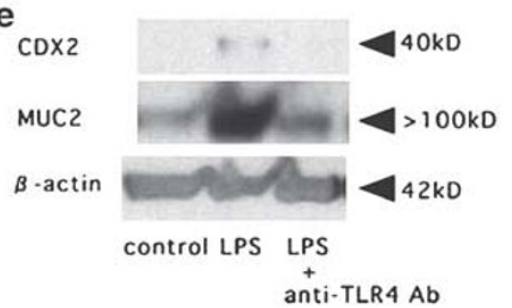

b
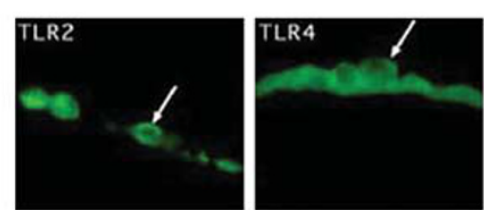

d

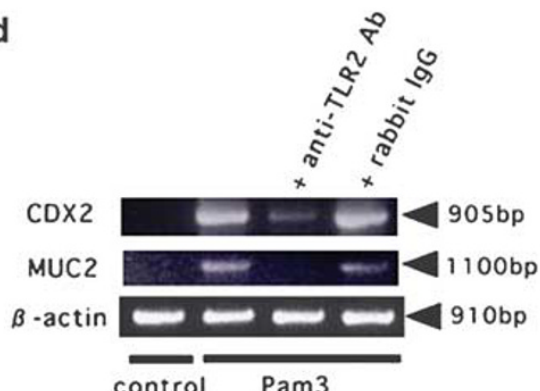

f

$\mathrm{fDx}^{\mathrm{CO}}$

MUC2

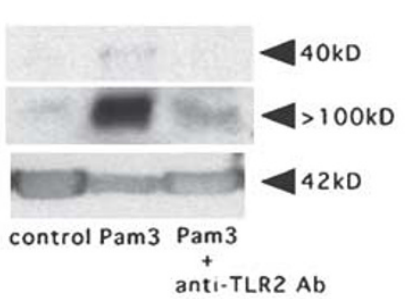

g

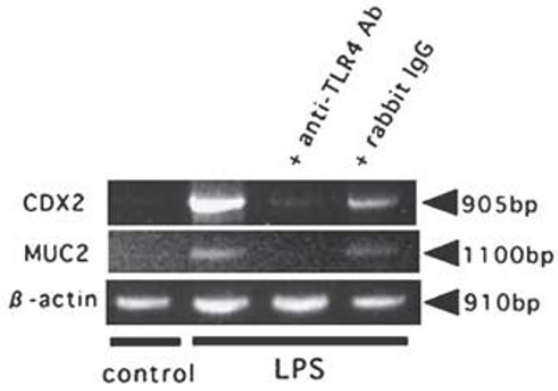

Figure 6 Expression of TLR2 and TLR4 mRNA and protein in cultured BECs and effects of anti-TLR antibody on PAMPsinduced CDX2 and MUC2 expression. (a-f) BECs from PCK rats. (g) BECs from control rats. (a) TLR2 and TLR4 mRNA are expressed at the predicted size (245 and 205 bp, respectively) in cultured BECs under baseline conditions, as shown by RT-PCR. (b) Membranous and cytoplasmic expression of TLR2 and TLR4 is detected in cultured BECs (arrows). Immunocytochemistry for TLR2 and TLR4. (c and d) Preincubation with anti-TLR4 or TLR2 antibody $(10 \mu \mathrm{g} / \mathrm{ml})$ for $30 \mathrm{~min}$ reduced $C D X 2$ and MUC2 mRNA expression induced by treatment with LPS $(10 \mu \mathrm{g} / \mathrm{ml})$ or synthetic lipopeptide Pam3 $(10 \mu \mathrm{g} / \mathrm{ml})$ for $6 \mathrm{~h}$, respectively. Normal rabbit lgG $(10 \mu \mathrm{g} / \mathrm{ml})$ did not affect CDX2 or MUC2 expression induced by LPS or Pam3. RT-PCR for CDX2 and MUC2. (e and $\mathbf{f}$ ) Preincubation with antiTLR4 or TLR2 antibody $(10 \mu \mathrm{g} / \mathrm{ml})$ for $1 \mathrm{~h}$ reduced $C D X 2$ and MUC2 protein expression induced by treatment with LPS $(10 \mu \mathrm{g} / \mathrm{ml})$ or Pam3 $(10 \mu \mathrm{g} / \mathrm{ml})$ for $72 \mathrm{~h}$, respectively. Western blotting for CDX2 and MUC2. (g) Preincubation with anti-TLR4 antibody $(10 \mu \mathrm{g} / \mathrm{ml})$ for $30 \mathrm{~min}$ reduced CDX2 and MUC2 mRNA expression induced by treatment with LPS $(10 \mu \mathrm{g} / \mathrm{ml})$ in cultured BECs from normal rats as seen in PCK rats (Figure 6c). Normal rabbit lgG $(10 \mu \mathrm{g} / \mathrm{ml})$ did not affect CDX2 or MUC2 expression induced by LPS. RT-PCR for CDX2 and MUC2. 
MUC2 expression. In fact, MG132, an inhibitor of NF- $\kappa \mathrm{B}$, inhibited CDX2 mRNA expression and also MUC2 mRNA expression in this study (Figure 7a). This raises the possibility that inhibition of NF- $\kappa \mathrm{B}$ leads indirectly to decreased expression of MUC2 mRNA via a decrease in CDX2 mRNA and also directly to decreased expression of MUC2 mRNA. Taken together, it seems plausible that although the activation of CDX2 may be the predominant pathway in the upregulation of MUC2 expression in rat BECs, there may be other pathway(s) leading to increased transcription of MUC2 in cultured BECs. More studies are mandatory to clarify this issue in BECs. Cultured BECs transfected with the CDX2 expres-

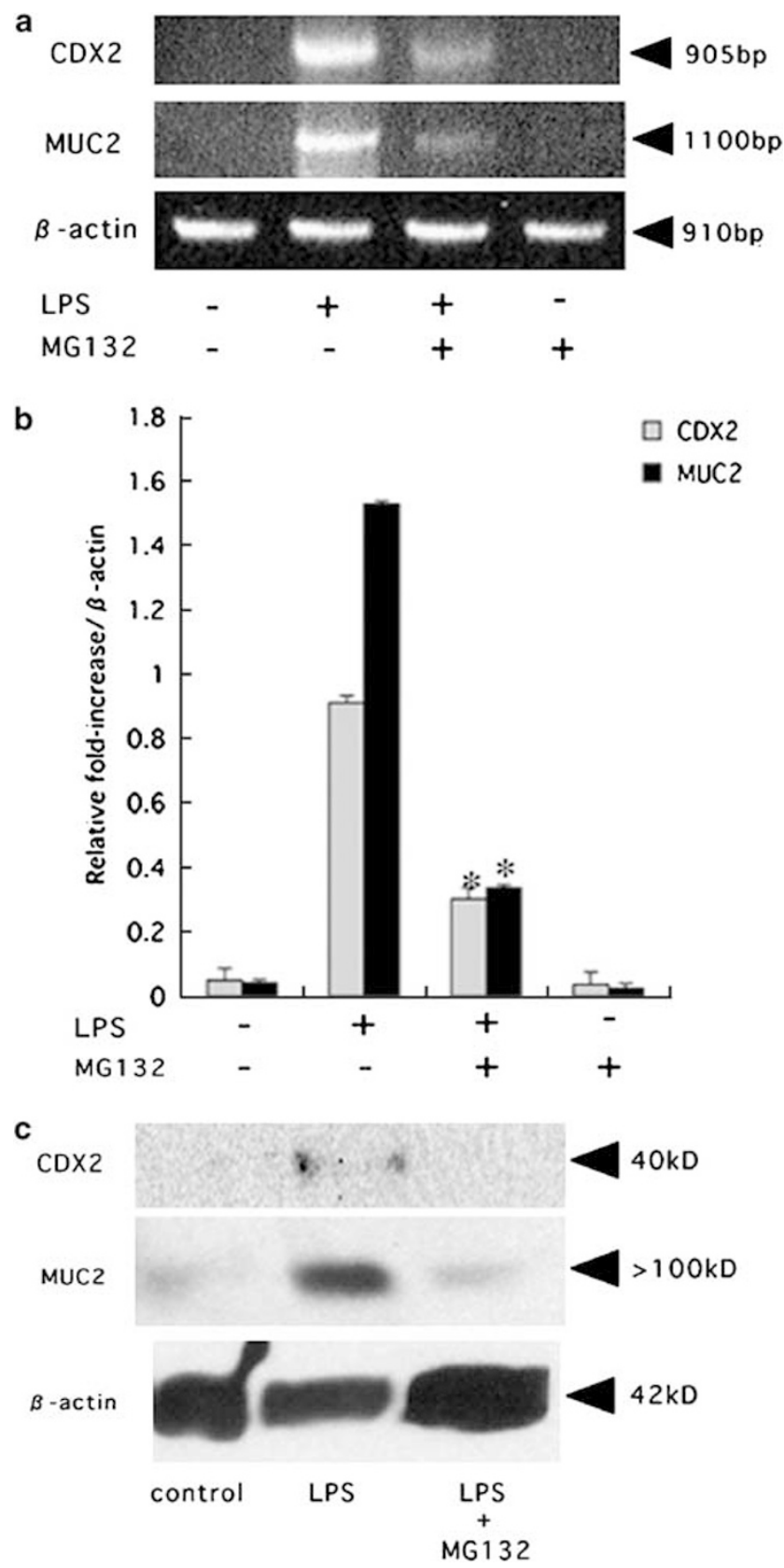

sion vector showed immunohistochemically CDX2 expression in the nucleus and MUC2 in the cytoplasm. In PCK rats, CDX2 and MUC2 were also expressed in the nucleus and cytoplasm of goblet cells, respectively. Taken together, the expression of MUC2 in cultured BECs and probably in goblet cells in metaplastic bile ducts may be mediated via upregulated CDX2. Columnar epithelium expressing nuclear CDX2 but not MUC2 around goblet cells in the bile ducts (Figure $2 \mathrm{a}-\mathrm{c}$ ) may be an early change of goblet cells, as CDX2 is also involved in the differentiation of goblet cells. ${ }^{6}$

Intestinal metaplasia is significantly involved in the pathogenesis of biliary diseases. For example, chronic cholangitis in hepatolithiasis, an intractable disease, shows intestinal and gastric metaplasia of lining BECs expressing MUC2. ${ }^{10-12,16}$ MUC2 is also expressed in the intraductal papillary neoplasm of bile ducts (IPNB) showing intraductal growth and secreting much mucin. ${ }^{1,37-41}$ IPNB is known to

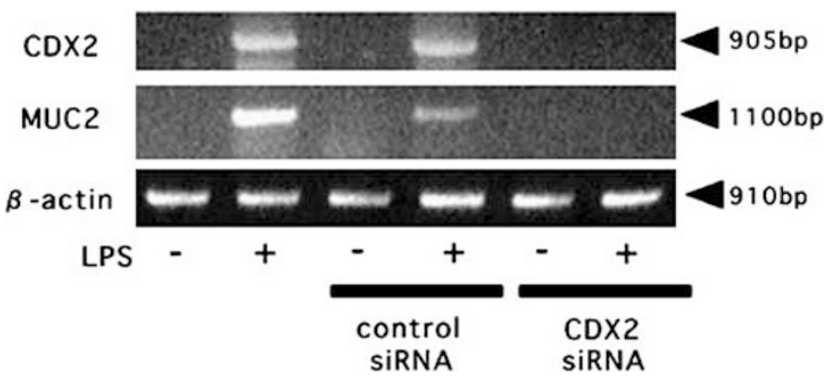

Figure 8 CDX2 and MUC2 mRNA expression in cultured BECs from PCK rats after transfection of CDX2 siRNA. By treatment with LPS $(10 \mu \mathrm{g} / \mathrm{ml})$, CDX2 and MUC2 mRNA expression were induced (left two lanes: control and LPS treatment). The expression of both CDX2 and MUC2 mRNA induced by LPS treatment disappeared when CDX2 siRNA was transfected in cultured BECs (right two lanes: control and LPS treatment), whereas neither expression in cultured BECs was inhibited by transfection of control siRNA (middle two lanes: control and LPS treatment). RT-PCR for CDX2 and MUC2.

Figure 7 Effect of MG132, an inhibitor of NF- $\kappa$ B, on LPS-induced CDX2 and MUC2 expression in cultured BECs from PCK rats. (a) CDX2 and MUC2 mRNA levels of cultured BECs incubated with LPS $(10 \mu \mathrm{g} / \mathrm{ml})$ for $6 \mathrm{~h}$ (2nd lane) were reduced in comparison with CDX2 and MUC2 mRNA levels in cultured BECs incubated with LPS $(10 \mu \mathrm{g} / \mathrm{ml})$ for $6 \mathrm{~h}$ after treatment with MG132 (1 $\mu \mathrm{M}$, an inhibitor of NF- $\kappa$ B) for 30 min (3rd lane). No significant expression of CDX2 or MUC2 mRNA was seen in the control (treatment with basic medium alone (1st lane) or on treatment with MG132 $(1 \mu \mathrm{M})$ alone (4th lane). Gel image of CDX2 and MUC2 mRNA expression. (b) NIH image of the gel image of CDX2 and MUC2 mRNA expression shown in (a). CDX2 mRNA and MUC2 mRNA levels were reduced to $30.2 \pm 3.4$ and $33.7 \pm 0.9 \%$ (2nd and 3rd columns), respectively (both, $<0.05$ ). Bars indicate mean \pm s.e.m. No significant expression of CDX2 or MUC2 mRNA was seen in the control (1st column) (treatment with basic medium alone) or on treatment with MG132 $(1 \mu \mathrm{M})$ alone (4th column). (c) CDX2 and MUC2 protein levels in cultured BECs incubated with LPS $(10 \mu \mathrm{g} / \mathrm{ml})$ for $30 \mathrm{~h}$ (middle lane) were markedly decreased when the cells were pretreated with MG132 (1 $\mathrm{mol} / \mathrm{l})$ for $1 \mathrm{~h}$ (right lane). The control without LPS treatment is the left lane. Western blotting for CDX2 and MUC2 protein. 
a

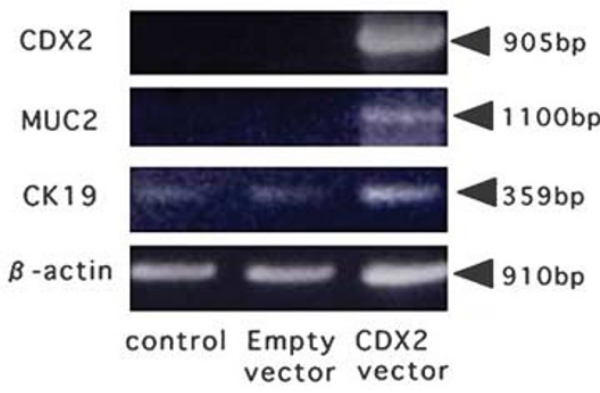

c
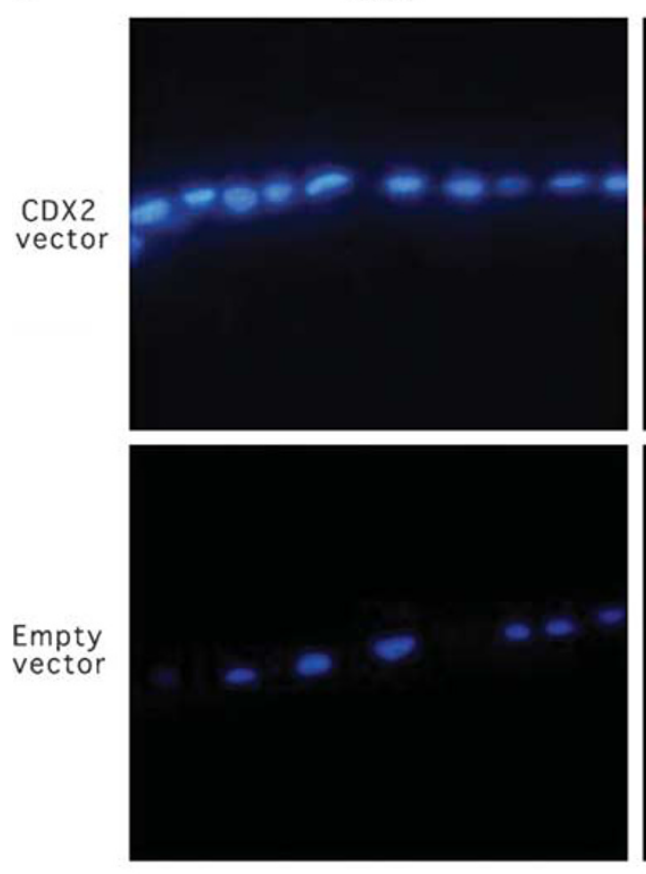

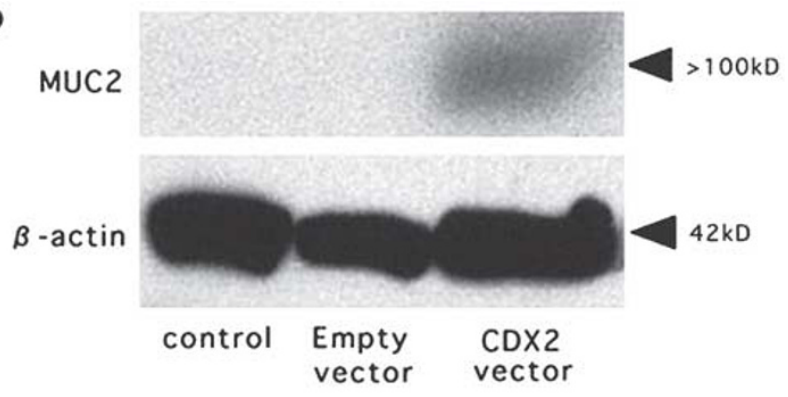

$\operatorname{CDX} 2$
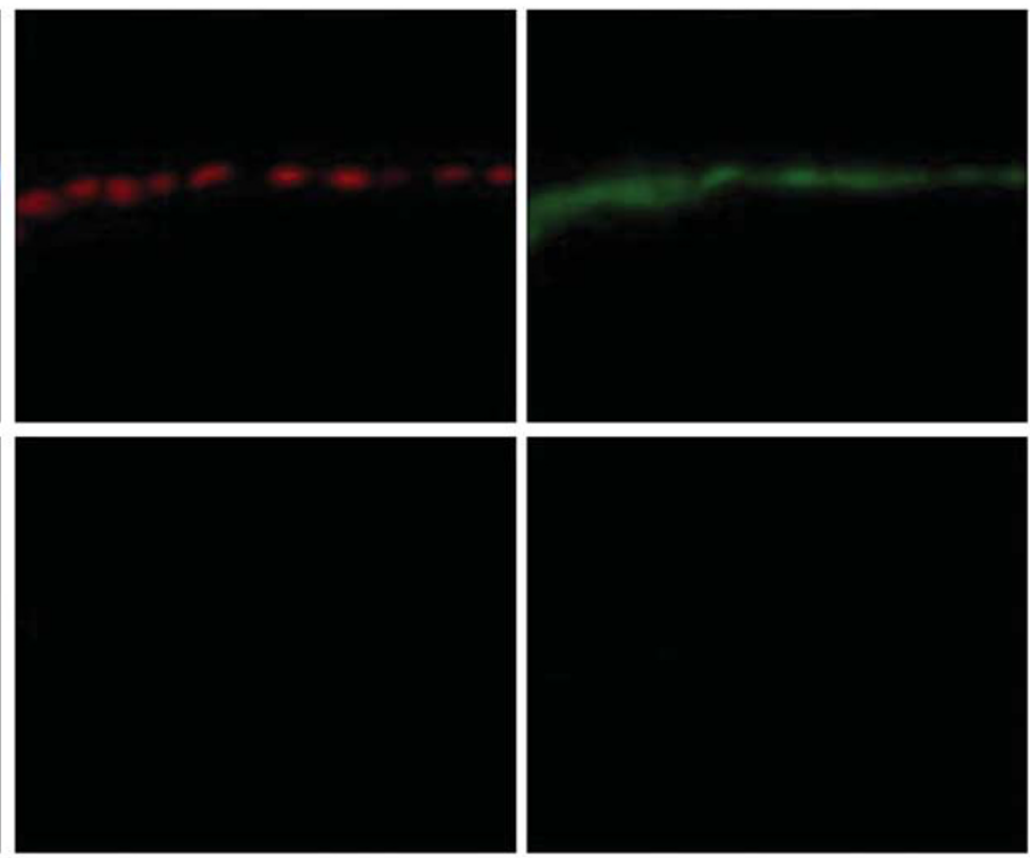

d

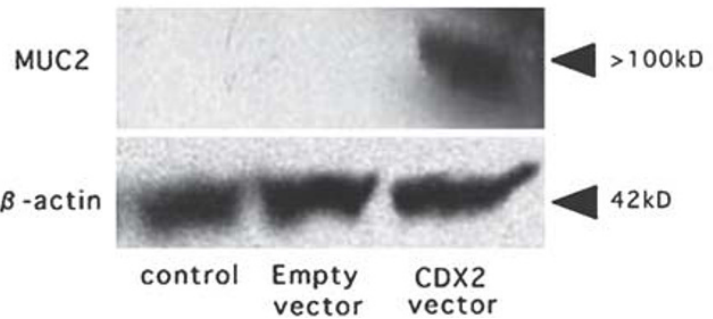

Figure 9 Effects of CDX2 expression vector transfection in cultured BECs. Cultured BECs were transiently transfected with the CDX2 expression vector or control vector without a CDX2 sequence (empty vector). (a-c) BECs from PCK rats. (d) BECs from control rats. (a) Transfection of the CDX2 expression vector induced CDX2 and MUC2 mRNA expression in cultured BECs (right lane). CDX2 and MUC2 mRNA were not detected in BECs with no transfection (left lane), or in those transfected with empty vector (middle lane). The expression level of CK19, a marker of biliary epithelium, was almost immutable after transfection of the CDX2 expression vector, the same as the $\beta$-actin mRNA expression. RT-PCR for CDX2, MUC2, and CK19. (b) MUC2 protein was expressed in cultured BECs with transfection of the CDX2 expression vector. No positive band of MUC2 protein was found on transfection of empty vector or without transfection. Western blotting for MUC2. (c) Positive staining of CDX2 (red) in the nucleus (upper and middle) and MUC2 (green) in the cytoplasm (upper and right) were seen in cultured BECs transfected with the CDX2 expression vector, whereas such expression of CDX2 and MUC2 was absent in cultured BECs transfected with the empty vector (lower lane). The nucleus of cultured cells was visualized with DAPI (left lane) with no immunostaining of CDX2 or MUC2. Fluorescence immunohistochemistry for CDX2 and MUC2. Original magnification, $\times 400$. (d) MUC2 protein was expressed in cultured BECs from control rats on transfection of the CDX2 expression vector as well as those from PCK rats. Western blotting for MUC2.

be associated with hepatolithiasis. ${ }^{39,40}$ So, therapeutic approaches targeting MUC2 and CDX2 would be promising in patients with these biliary diseases.
In conclusion, this study using PCK rats showed that the interaction of PAMPs with TLR2/4 followed by the activation of $\mathrm{NF}-\kappa \mathrm{B}$ led to the upregulation of CDX2 expression and 
expression of MUC2 in cultured BECs, and this scenario may occur in the development of intestinal metaplasia in chronic suppurative cholangitis.

1. Ishikawa A, Sasaki M, Ohira S, et al. Aberrant expression of CDX2 is closely related to the intestinal metaplasia and MUC2 expression in intraductal papillary neoplasm of the liver in hepatolithiasis. Lab Invest 2004;84:629-638.

2. Eda A, Osawa H, Satoh $K$, et al. Aberrant expression of CDX2 in Barrett's epithelium and inflammatory esophageal mucosa. J Gastroenterol 2003;38:14-22.

3. Satoh K, Mutoh H, Eda A, et al. Aberrant expression of CDX2 in the gastric mucosa with and without intestinal metaplasia: effect of eradication of Helicobacter pylori. Helicobacter 2002;7:192-198.

4. Eda A, Osawa H, Yanaka l, et al. Expression of homeobox gene CDX2 precedes that of CDX1 during the progression of intestinal metaplasia. J Gastroenterol 2002;37:94-100.

5. Silberg DG, Sullivan J, Kang E, et al. Cdx2 ectopic expression induces gastric intestinal metaplasia in transgenic mice. Gastroenterology 2002;122:689-696

6. Yamamoto $\mathrm{H}$, Bai YQ, Yuasa $\mathrm{Y}$. Homeodomain protein $\mathrm{CDX} 2$ regulates goblet-specific MUC2 gene expression. Biochem Biophys Res Commun 2003;300:813-818.

7. Hong SM, Cho H, Moskaluk CA, et al. CDX2 and MUC2 protein expression in extrahepatic bile duct carcinoma. Am J Clin Pathol 2005; 124:361-370.

8. Kazumori $\mathrm{H}$, Ishihara $\mathrm{S}$, Rumi $\mathrm{MA}$, et al. Bile acids directly augment caudal related homeobox gene $\mathrm{Cd} \times 2$ expression in oesophageal keratinocytes in Barrett's epithelium. Gut 2006;55:16-25

9. Tatsuta $\mathrm{T}$, Mukaisho $\mathrm{K}$, Sugihara $\mathrm{H}$, et al. Expression of $\mathrm{Cdx2}$ in early GRCL of Barrett's esophagus induced in rats by duodenal reflux. Dig Dis Sci 2005:50:425-431.

10. Nakanuma Y, Yamaguchi K, Ohta G, et al. Pathologic features of hepatolithiasis in Japan. Hum Pathol 1988;19:1181-1186.

11. Terada T, Nakanuma Y. Morphological examination of intrahepatic bile ducts in hepatolithiasis. Virchows Arch 1988;414:167-176.

12. Koga $A$, Ichimiya $H$, Yamaguchi $K$, et al. Hepatolithiasis associated with cholangiocarcinoma. Possible etiologic significance. Cancer 1985;55:2826-2829.

13. Chu KM, Lo CM, Liu CL, et al. Malignancy associated with hepatolithiasis. Hepatogastroenterology 1997:44:352-357.

14. Sasaki M, Nakanuma Y, Kim YS. Expression of apomucins in the intrahepatic biliary tree in hepatolithiasis differs from that in normal liver and extrahepatic biliary obstruction. Hepatology 1998;27:54-61.

15. Portman BC, Nakanuma Y. Diseases of bile ducts. In: MacSween RNM, Burt AD, Portman BC, Ishak KG, Scheuer PJ, Anthody PP (eds) Pathology of the Liver, 4th edn. Churchill Livingstone: London, 2001, pp 435-506.

16. Kurumaya H, Terada T, Nakanuma Y. 'Metaplastic lesions' in intrahepatic bile ducts in hepatolithiasis: a histochemical and immunohistochemical study. J Gastroenterol Hepatol 1990;5:530-536.

17. Sasaki M, Ikeda H, Nakanuma Y. Expression profiles of MUC mucin core protein in the intrahepatic biliary system: physiological distribution and pathological significance. Acta Histochem Cytochem 2005;38: 295-303.

18. Zen $Y$, Sasaki M, Fujii T, et al. Different expression patterns of mucin core proteins and cytokeratins during intrahepatic cholangiocarcinogenesis from biliary intraepithelial neoplasia and intraductal papillary neoplasm of the bile duct-an immunohistochemical study of 110 cases of hepatolithiasis. J Hepato 2006:44:350-358.

19. Sheen-Chen $\mathrm{S}$, Chen W, Eng $\mathrm{H}$, et al. Bacteriology and antimicrobial choice in hepatolithiasis. Am J Infect Control 2000;28:298-301.

20. Tabata M, Nakayama F. Bacteriology of hepatolithiasis. Prog Clin Biol Res 1984;152:163-174

21. Zen Y, Harada K, Sasaki M, et al. Lipopolysaccharide induces overexpression of MUC2 and MUC5AC in cultured biliary epithelial cells: possible key phenomenon of hepatolithiasis. Am J Pathol 2002;161:1475-1484.

22. Schwandner $\mathrm{R}$, Dziarski $\mathrm{R}$, Wesche $\mathrm{H}$, et al. Peptidoglycan- and lipoteichoic acid-induced cell activation is mediated by Toll-like receptor 2. J Biol Chem 1999;274:17406-17409.

23. Faure $E$, Equils $O$, Sieling $P A$, et al. Bacterial lipopolysaccharide activates NF-kappaB through Toll-like receptor 4 (TLR-4) in cultured human dermal endothelial cells. Differential expression of TLR-4 and TLR-2 in endothelial cells. J Biol Chem 2000;275 11058-11063.

24. Siedlar M, Frankenberger M, Benkhart $E$, et al. Tolerance induced by the lipopeptide Pam3Cys is due to ablation of IL-1R-associated kinase1. J Immunol 2004;173:2736-2745.

25. Sanzen T, Harada K, Yasoshima M, et al. Polycystic kidney rat is a nove animal model of Caroli's disease associated with congenital hepatic fibrosis. Am J Pathol 2001;158:1605-1612.

26. Harada K, Tsuneyama K, Sudo Y, et al. Molecular identification of bacterial $16 \mathrm{~S}$ ribosomal RNA gene in liver tissue of primary biliary cirrhosis: is Propionibacterium acnes involved in granuloma formation? Hepatology 2001;33:530-536.

27. Kim DY, Takeuchi $\mathrm{K}$, Ishinaga $\mathrm{H}$, et al. Roxithromycin suppresses mucin gene expression in epithelial cells. Pharmacology 2004;72:6-11.

28. Ishinaga $\mathrm{H}$, Takeuchi $\mathrm{K}$, Kishioka $\mathrm{C}$, et al. Pranlukast inhibits NF-kappaB activation and MUC2 gene expression in cultured human epithelial cells. Pharmacology 2005;73:89-96.

29. Marchetti M, Caliot E, Pringault E. Chronic acid exposure leads to activation of the $\mathrm{cd} \times 2$ intestinal homeobox gene in a long-term culture of mouse esophageal keratinocytes. J Cell Sci 2003;116:1429-1436.

30. Manzo BA, Crabtree JE, Fiona CM, et al. Helicobacter pylori regulates the expression of inhibitors of DNA binding (Id) proteins by gastric epithelial cells. Microbes Infect 2006;8:1064-1074.

31. Jono $\mathrm{H}$, Shuto $\mathrm{T}, \mathrm{Xu} \mathrm{H}$, et al. Transforming growth factor-beta-Smad signaling pathway cooperates with NF-kappa B to mediate nontypeable Haemophilus influenzae-induced MUC2 mucin transcription. J Biol Chem 2002;277:45547-45557.

32. Li JD, Feng W, Gallup M, et al. Activation of NF-kappaB via a Src dependent Ras-MAPK-pp90rsk pathway is required for Pseudomonas aeruginosa-induced mucin overproduction in epithelial cells. Proc Natl Acad Sci USA 1998;95:5718-5723.

33. Ding SZ, Torok AM, Smith Jr MF, et al. Toll-like receptor 2-mediated gene expression in epithelial cells during Helicobacter pylori infection. Helicobacter 2005;10:193-204.

34. Ishihara S, Rumi MA, Kadowaki Y, et al. Essential role of MD-2 in TLR4dependent signaling during Helicobacter pylori-associated gastritis. J Immunol 2004;173:1406-1416.

35. Harada K, Ohira S, Isse K, et al. Lipopolysaccharide activates nuclear factor-kappaB through Toll-like receptors and related molecules in cultured biliary epithelial cells. Lab Invest 2003;83:1657-1667.

36. Ahn DH, Crawley SC, Hokari R, et al. TNF-alpha activates MUC2 transcription via NF-kappaB but inhibits via JNK activation. Cell Physiol Biochem 2005;15:29-40.

37. Yeh TS, Tseng JH, Chen TC, et al. Characterization of intrahepatic cholangiocarcinoma of the intraductal growth-type and its precursor lesions. Hepatology 2005;42:657-664.

38. Chu PG, Schwarz RE, Lau SK, et al. Immunohistochemical staining in the diagnosis of pancreatobiliary and ampulla of Vater adenocarcinoma: application of CDX2, CK17, MUC1, and MUC2. Am J Surg Pathol 2005;29:359-367.

39. Shimonishi T, Zen Y, Chen TC, et al. Increasing expression of gastrointestinal phenotypes and p53 along with histologic progression of intraductal papillary neoplasia of the liver. Hum Pathol 2002;33: 503-511.

40. Nakanuma $Y$, Terada T, Tanaka $Y$, et al. Are hepatolithiasis and cholangiocarcinoma aetiologically related? A morphological study of 12 cases of hepatolithiasis associated with cholangiocarcinoma. Virchows Arch A Pathol Anat Histopathol 1985;406:45-58.

41. Chen TC, Nakanuma Y, Zen Y, et al. Intraductal papillary neoplasia of the liver associated with hepatolithiasis. Hepatology 2001;34: 651-658. 